\title{
BLATTELLA ASAHINAI INTRODUCED INTO FLORIDA (BLATTARIA: BLATTELLIDAE).
}

\author{
By Louis M. Roth* \\ Museum of Comparative Zoology, Harvard University \\ Cambridge, MA 02138
}

On March 3, 1986, Dr. Philip G. Koehler of the Florida Extension Service, University of Florida, sent me some cockroaches from Lakeland, Florida, for identification. These had been submitted to him by Mr. Ed Shower, a pest control worker, who referred to them as German cockroaches, but pointed out that they were unusual because they flew readily and were common outdoors. Until now only 2 species of Blattella occur in the United States, namely, vaga Hebard (India, Afghanistan, Pakistan, Sri Lanka, Mexico, and the United States [California, Arizona, Texas]), and the cosmopolitan germanica (Linn.), both originating from Asia (Roth, 1985).

I decided that the "unusual germanica" could be Blattella beybienkoi Roth, which is found in Sri Lanka, Andaman Islands, Burma, Chagos Archipelago, China, India, and Thailand (Roth, 1985). However, it also agreed with specimens of Blattella asahinai Mizukubo, described from Okinawa (Mizukubo, 1981; Asahina, 1985). I was unaware of this species when I completed my revision of Blattella and submitted it for publication in 1982.

I sent several Lakeland specimens to Dr. Mizukubo, who concluded that they are asahinai. He also made a detailed comparison of Sri Lanka paratypes of B. beybienkoi, and asahinai from Florida and Okinawa, and could find no significant differences between the two species, which I am here synonymizing.

My (Roth, 1970) attempts to cross B. germanica with 6 other species of Blattella, namely, bisignata (Brunner), lituricollis (Walker), sauteri (Karny), roederi Roth [as sp. C], humbertiana (Saussure) [as sp. D], and lobiventris [as $\mathrm{sp}$. E], were generally unsuccessful. B. germanica males mated only once with bisignata

\footnotetext{
*Correspondence: 81 Brush Hill Road, Box 238, Sherborn, MA 01770
} Manuscript received by the editor August 23, 1986 

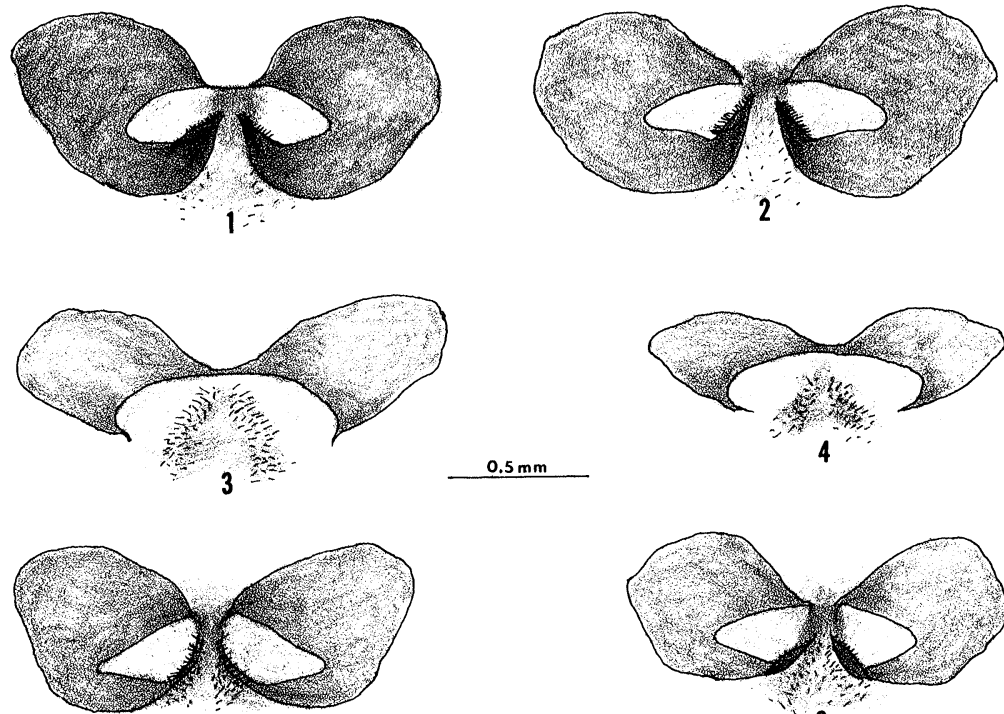

5
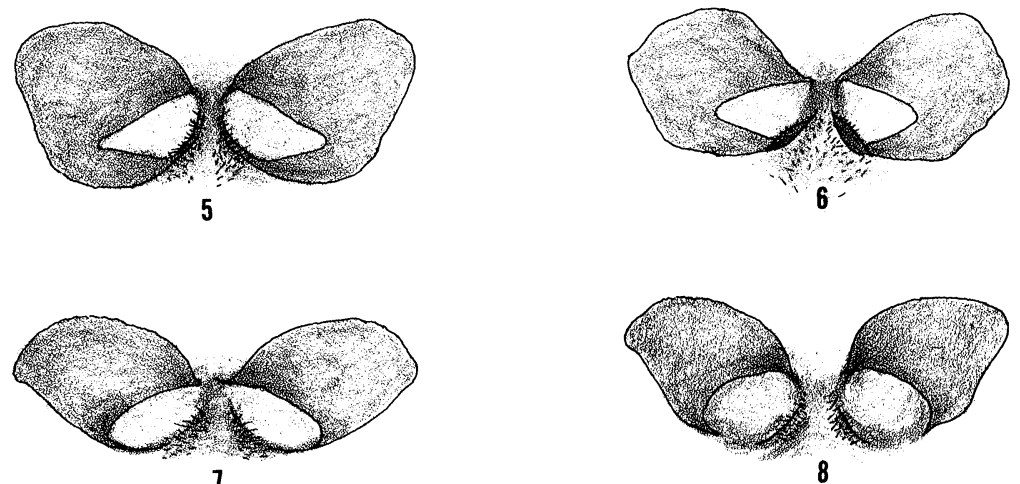

Figs. 1-5. Tergal gland reservoirs on abdominal segment 8 of Blattella spp.: Figs. 1, 2. B. germanica from Lakeland, Fla. Figs. 3, 4. B. asahinai from Lakeland and Okinawa, respectively. Figs. $5-8 . F_{1}$ males resulting from a cross between male asahinai and female germanica.

and a male of the latter mated once with a female germanica. No offspring resulted from these 2 crosses. However, in the laboratory, B. asahinai males do cross readily with germanica females producing $F_{1}$ offspring which, to date, have produced $F_{2}$ nymphs. Attempts to produce offspring from the opposite cross of germanica males and asahinai females, have been unsuccessful (Patterson, et al., 1986); these results suggest that the 2 species are distinct, but very closely related.

One of the best diagnostic morphological characters for distinguishing asahinai from germanica is the shape ( $\mathrm{KOH}$ preparation) 
of the male tergal gland reservoirs on the eighth abdominal segment (cp. Figs. 1 and 2 with Figs. 3 and 4). Although there is some variation in the shapes of these sacs in germanica (see Figs. 6, 7, in Roth, 1985), their posterior margins curve cephalad where they may or may not join with the anterior margins. In asahinai the sacs are connected anteriorly, but their hind margins are widely separated (see Figs. 12B, C, 13A-F, in Roth, 1985). The $\mathrm{F}_{1}$ males resulting from crossing male asahinai with female germanica have reservoirs which are more typical of germanica (Figs. 5-8).

Blattella asahinai is very widely distributed. On Okinawa it is usually found among dead leaves and litter on the ground, and occasionally was collected by sweeping over tree blossoms (Mizukubo, 1981). In Florida it is considered to be a potential pest since it is found in large numbers in lawns, on bushes, and invades houses. It is now being studied by members of the USDA-ARS, and the University of Florida, Household Insects Project (Patterson et al., 1986).

\section{ACKNOWLEDGMENTS}

I thank the following: Dr. Takayuki Mizukubo, National Institute of Agro-Environmental Sciences, Japan, for his opinions concerning B. asahinai from Florida and B. beybienkoi; Dr. Syoziro Asahina, retired, for specimens of $B$. asahinai from Okinawa; $\mathrm{Mr}$. Donald Azuma, Academy of Natural Sciences of Philadelphia for sending paratypes of B. beybienkoi to Dr. Mizukubo at my request; Dr. R. S. Patterson, Dr. R. J. Brenner, and Dr. P. G. Koehler, USDA-ARS, Gainesville, Florida, and the University of Florida, for specimens and biological information of asahinai from Florida and for $F_{1}$ specimens resulting from a cross between asahinai and germanica.

I am grateful to The American Philosophical Society for partial support.

\section{REFERENCES}

Asahina, S.

1985. Taxonomic notes on Japanese Blattaria, XIV. Descriptions of one new and four little-known species. Chô Chô, pub. by Gen-Gen Sha, Kitakyushu-shi, Wakamatsu, Miyamaru, Nippon, 8: 19-26.

Mizukubo, T.

1981. A revision of the genus Blattella (Blattaria: Blattellidae) of Japan. 1. Terminology of the male genitalia and description of a new species from Okinawa Island. Esakia, 17: 149-159. 
Patterson, R. S., P. G. Koehler, and R. J. Brenner.

1986. Personal communication.

Roth, L. M.

1970. Interspecific mating in Blattaria. Ann. Ent. Soc. Amer. 63: 1282-1285.

Roth, L. M.

1985. A taxonomic revision of the genus Blattella Caudell (Dictyoptera, Blattaria: Blattellidae). Entomol. scand. Suppl. No. 22: 1-221. 

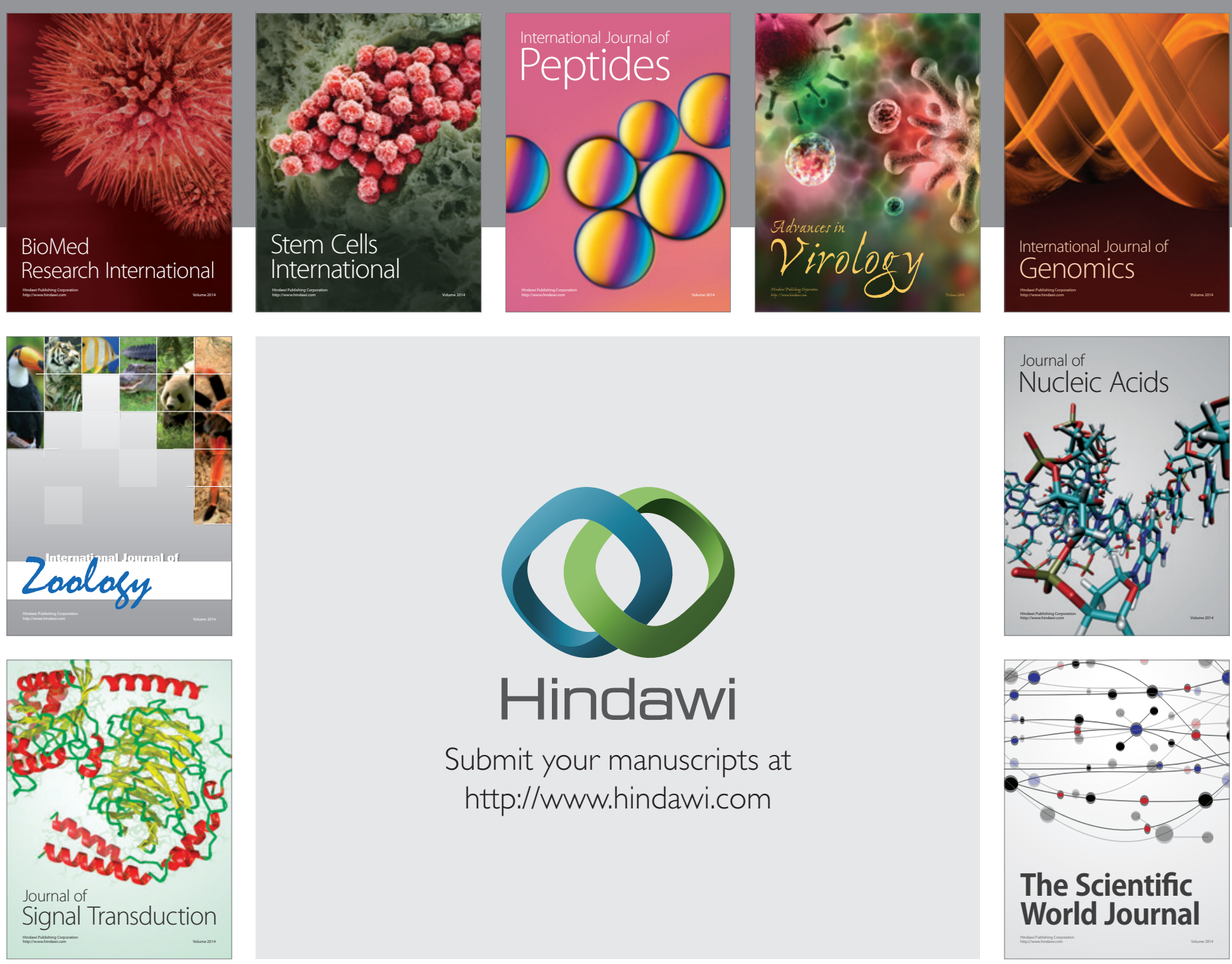

Submit your manuscripts at

http://www.hindawi.com
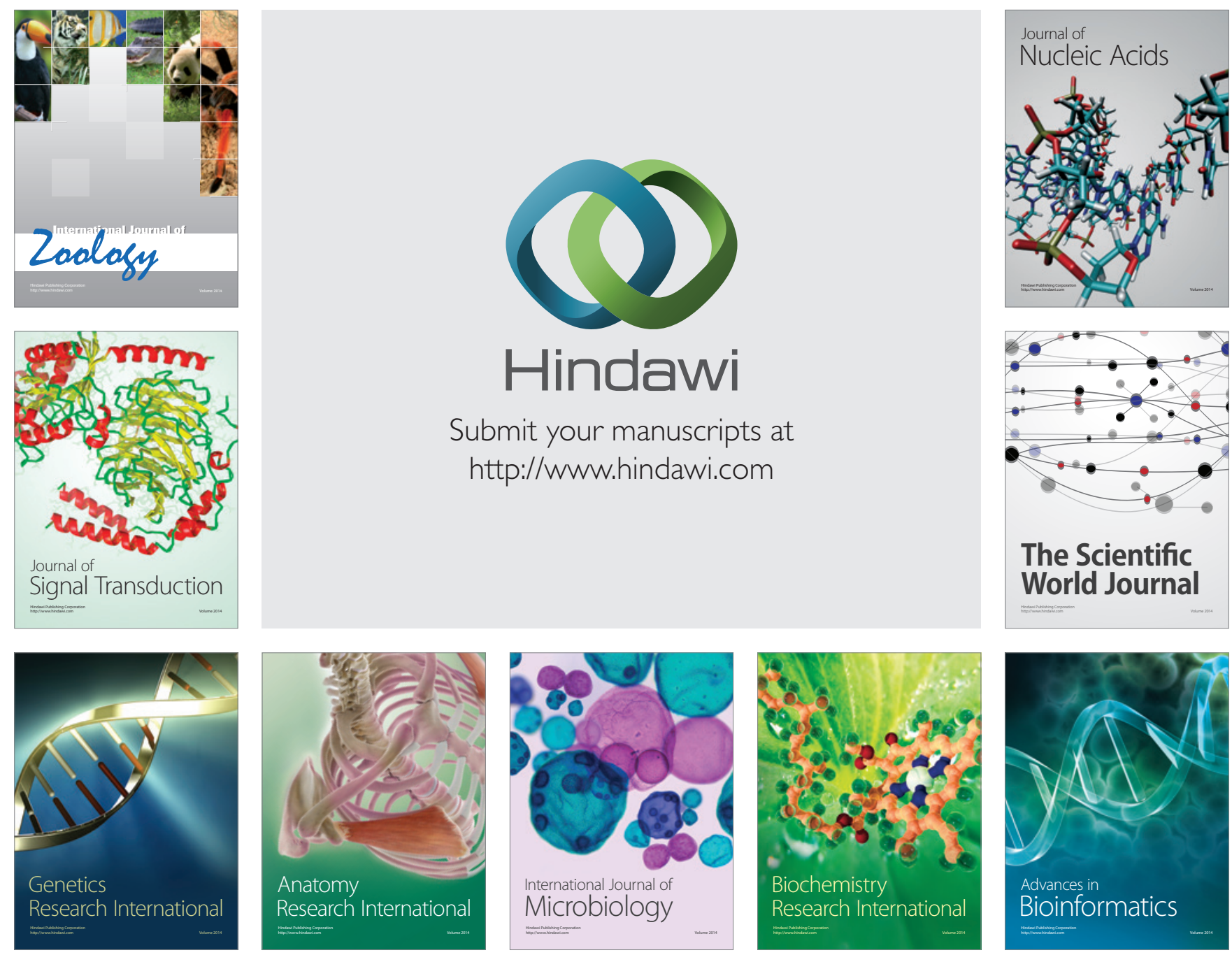

The Scientific World Journal
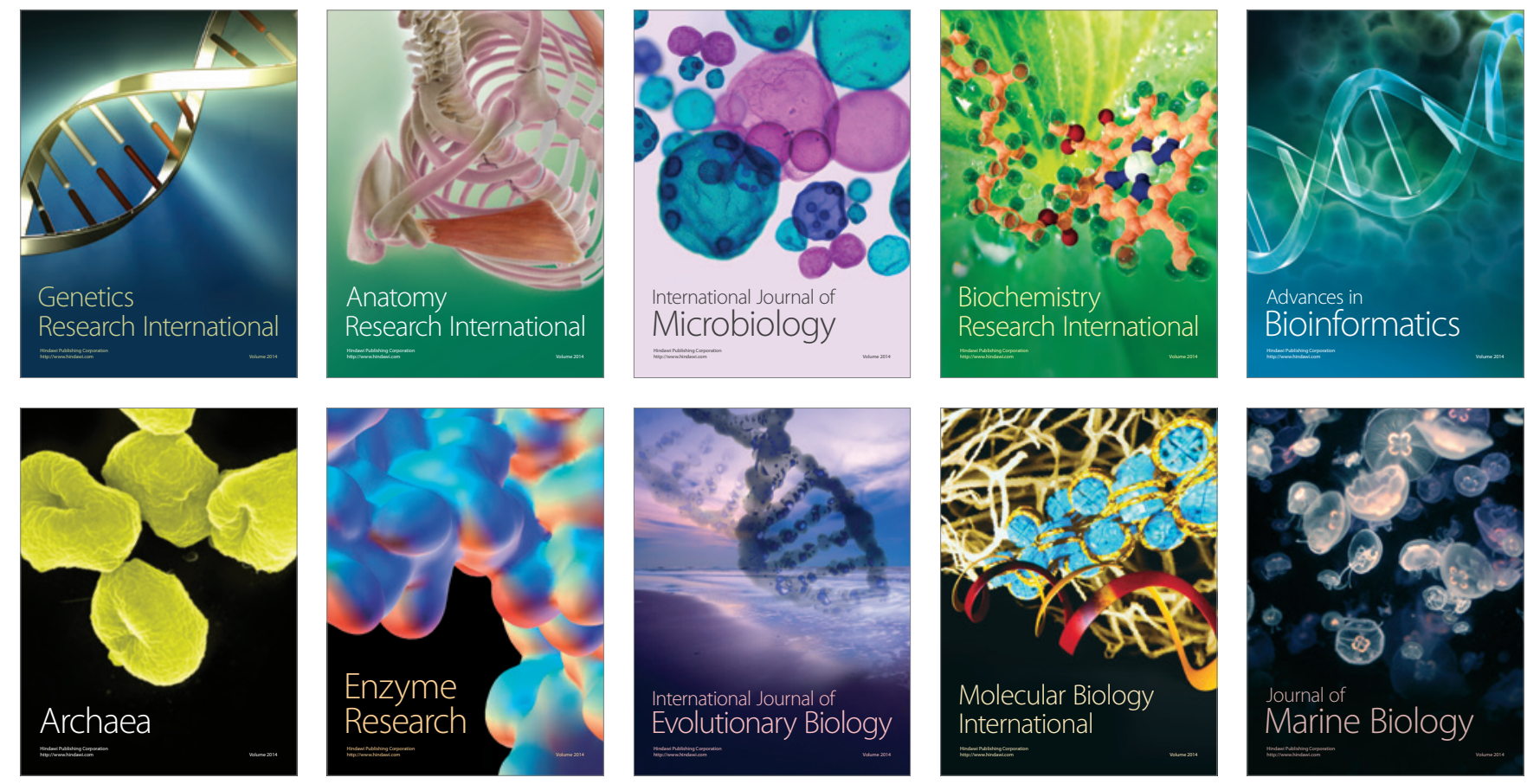